\title{
Effect of Donor/Recipient Body Weight Mismatch on Patient and Graft Outcome in Living-Donor Kidney Transplantation
}

\author{
Amgad E. El-Agroudy Nabil A. Hassan Mohamed A. Bakr \\ Mohamed A. Foda Ahmed A. Shokeir Ahmed B. Shehab El-Dein \\ Mohamed A. Ghoneim \\ Urology and Nephrology Center, Mansoura University, Mansoura, Egypt
}

\section{Key Words}

Living donor $\cdot$ Weight $\cdot$ Kidney transplantation

\begin{abstract}
Background/Aims: There have been conflicting reports showing that kidneys from small donors may be at risk for graft loss if they are transplanted into large recipients. The aim of this work was to examine the donor/recipient body weight ratio (D/RBWR) on patient and graft outcome. Methods: During the period from January 1990 to January 2002, 856 kidney transplants were performed. Of these, 776 kidney transplant recipients were selected after exclusion of pediatric, second transplant patients and those with a body mass index of $\geq 35$. All patients achieved a minimum follow-up of 1-year. According to D/RBWR, patients were divided into 3 groups: low $(\leq 0.9)$, medium (0.91-1.2) and high ( $\geq 1.2)$. Data were collected on graft function, acute and chronic rejection, post-transplant complications, and 1- and 5-year graft and patient survival. Results: There was a statistically significant increase in the incidence of chronic rejection, post-transplant hypertension and diabetes mellitus in the low group. The incidence and frequency of acute rejection episodes were nearly the same in the 3 groups. Graft function, estimated by serum creatinine at 1 year, was significantly lower in the low group. The 5-year graft
\end{abstract}

\section{KARGER}

Fax +4161306 1234

E-Mail karger@karger.ch

www.karger.com
(C) 2003 S. Karger AG, Basel

0250-8095/03/0235-0294\$19.50/0

Accessible online at:

www. karger.com/ajn and patient survival was $71,80,88$ and 81,85 and $92 \%$, in the low, medium and high groups, respectively. Conclusions: We conclude that a low D/RBWR may contribute to inferior long-term renal allograft survival. The hyperfiltration hypothesis due to low nephron mass in the low D/RBWR group may explain these findings.

Copyright $\odot 2003$ S. Karger AG, Basel

\section{Introduction}

The hyperfiltration theory (originally proposed by Brenner and Milford [1]) predicts that renal function gradually decreases with time, and that this process may be accelerated by reduced nephron mass. This theory has received support from animal models [2], but evidence in humans is indirect.

Long-term allograft loss is determined by a number of factors, with increasing attention being directed in recent years towards non-immunologic factors [3]. If the hyperfiltration theory applies to transplantation in humans, it would be expected to result in decreased allograft survival in renal grafts in which significant under-dosing was present. Limited support is derived from the observation that situations in which donor nephron mass is reduced are associated with poorer graft outcome. These include female to male transplants, pediatric kidneys trans-
Dr. Amgad E. El-Agroudy, MD

Urology and Nephrology Center, Mansoura University

Mansoura (Egypt)

Tel. +20502262222, Fax +20502263717

E-Mail amgadelbaz@ahram0505.net 
planted into adults, and older kidneys [4-6]. Also, it has been suggested that a relatively small kidney may not fit a large recipient and that the cause of chronic kidney graft failure may be due to the discrepancy between the mass of the grafted kidney and that of the recipient, giving rise to glomerular hyperfiltration. In fact, chronic hyperfiltration together with reduced functioning kidney mass might damage the graft, initiating a vicious circle of a further reduction in renal mass which in turn causes more significant hyperfiltration leading to a progressive decline in the glomerular filtration rate, proteinuria, hypertension and eventually chronic graft failure. Several small studies have suggested a correlation between the estimated nephron mass and transplant outcome [7-12], however, not all agree with this suggestion $[12,13]$ on the long-term or even short-term outcome $[14,15]$. Most of these studies were on cadaveric donors and include a small number of patients.

Kidney weight and body weight correlate directly [16, 17], so the ratio between the weight of the kidney graft and that of the recipient may be roughly expressed by the ratio between the body weights of the donor and the recipient. Thus, the donor/recipient body weight ratio (D/RBWR) should be considered when matching grafts to recipients.

We retrospectively investigated the importance of D/RBWR for the short- and long-term outcome of livedonor kidney transplants.

\section{Patients and Methods}

From January 1990 to January 2002, 856 nondiabetic patients received living-donor kidney transplants at our center. After exclusion of pediatric patients (age $\leq 15$ years), second transplant recipients and those with body mass index of $\geq 35,776$ kidney transplant recipients were selected for this retrospective study. All patients achieved a minimum 1-year follow-up.

As the body weights of dialyzed patients vary with time, and differences may amount to many kilograms, we considered the recipient body weight at the time of transplantation (dry body weight). The D/RBWR in our series ranged between 0.56 and 2.5 (median 1.13). According to these findings, we classified the patients into 3 groups: low D/RBWR $(<0.9)$, medium D/RBWR (between 0.91 and 1.2), and high D/RBWR (>1.2), accounting for patients who received kidneys from smaller, roughly comparable, and larger donors, respectively. The numbers of patients were 110 in the low group, 355 in the medium group, and 311 in the high group.

Clinical records of all kidney transplant recipients were reviewed for demographic information, recipient age and gender, donor age and gender, causes of end-stage kidney disease, HLA-A, B and DR mismatching, pretransplant hypertension, pre-emptive renal transplantation, type of immunosuppression, number and severity of acute rejection episodes, delayed graft function, acute tubular necro- sis, chronic allograft nephropathy, medical complications such as hypertension, diabetes mellitus, infections and proteinuria, and surgical complications such as wound infection, dehiscence, and urological complications.

All the patients received $500 \mathrm{mg}$ methylprednisolone before and on the day of transplantation, and then oral prednisolone was given at $3.5 \mathrm{mg} / \mathrm{kg} /$ day for 2 days, then $1.5 \mathrm{mg} / \mathrm{kg} /$ day for 5 days, which was then tapered until it reached $0.15 \mathrm{mg} / \mathrm{kg} / \mathrm{day}$ from the 9th month onwards. Cyclosporin A (CsA) was given 2 days before transplantation at a dose of $8 \mathrm{mg} / \mathrm{kg} /$ day in two divided doses and then the dosages were adjusted to keep the whole blood trough level between 200 and $300 \mathrm{ng} / \mathrm{ml}$ during the first 2 months, and then between 100 and $150 \mathrm{ng} / \mathrm{ml}$ thereafter using monoclonal antibodies (TDx, Abbott Diagnostics, Lake Forest, Ill., USA). All acute rejection episodes were treated with $500 \mathrm{mg}$ methylprednisolone pulses for 5 days.

Patient and graft survivals were evaluated by means of KaplanMeier survival curves. When evaluating patient survival, patients who lost their grafts were excluded at the time of graft loss, and when evaluating graft survival, patients who died with functioning grafts were excluded at the date of death. The causes of death with functioning grafts was evaluated in all groups.

\section{Statistical Analysis}

Statistical analysis was carried out using SPSS for Windows packages (release 10). One-way analysis of variance was used to compare mean values in the 3 groups; while Kruskal-Wallis test and $\chi^{2}$ tests were used for categorical data. Kaplan-Meier curves were constructed for patient and graft survival. All values are expressed as mean values $\pm \mathrm{SD}$ or as percentages, unless otherwise specified. A $p$ value of $<0.05$ was considered significant.

\section{Results}

\section{Demographic Characteristics}

There were no differences in demographic variables with respect to recipient age, donor age, causes of endstage renal disease and donor source (table 1). There were more male than female recipients in the low group; however, this was not statistically significant $(p=0.08)$. The overall number of female patients in our series of 856 transplants performed between January 1991 and January 2002 is $146(17.1 \%)$, but after considering the exclusion criteria the number of female patients decreased to $74(9.5 \%)$ as a result of the large number of female patients with a body mass index of $>35$. The distribution of recipient and donor sizes is not random, and the pattern suggests that there is more than the expected recipient and donor size matching as illustrated in table 1. Some of the effect of donor-recipient size matching may be due to an effect of donor-recipient age-matching, because donor size and age correlate; however, there was no significant difference in the mean donor age distribution in our groups (table 1). 
Table 1. Patient characteristics

\begin{tabular}{|c|c|c|c|c|}
\hline & $\begin{array}{l}\text { Low group } \\
(\mathrm{n}=110)\end{array}$ & $\begin{array}{l}\text { Medium group } \\
(\mathrm{n}=355)\end{array}$ & $\begin{array}{l}\text { High group } \\
(\mathrm{n}=311)\end{array}$ & $\mathrm{p}$ \\
\hline \multicolumn{5}{|l|}{ Recipient age, years } \\
\hline Mean $\pm \mathrm{SD}$ & $34.9 \pm 7.8$ & $33.4 \pm 8.0$ & $33.4 \pm 7.8$ & \multirow[t]{2}{*}{0.17} \\
\hline Range & $19-62$ & $18-57$ & $18-55$ & \\
\hline \multicolumn{5}{|l|}{ Donor age, years } \\
\hline Mean $\pm \mathrm{SD}$ & $36.3 \pm 8.6$ & $36.2 \pm 9.8$ & $36.9 \pm 7.8$ & \multirow{2}{*}{0.51} \\
\hline Range & $21-60$ & $21-62$ & $21-62$ & \\
\hline Male recipients & $100(91 \%)$ & $322(91 \%)$ & $280(90 \%)$ & 0.23 \\
\hline Male donors & $48(44 \%)$ & $189(53 \%)$ & $143(46 \%)$ & 0.08 \\
\hline Related donors & $98(89 \%)$ & $319(90 \%)$ & $282(91 \%)$ & 0.21 \\
\hline Pre-emptive $T x$ & $7(6.4 \%)$ & $23(6.5 \%)$ & $11(3.5 \%)$ & 0.21 \\
\hline \multicolumn{5}{|l|}{ Causes of ESRD } \\
\hline Glomerular & $11(10 \%)$ & $28(8 \%)$ & $35(11 \%)$ & \multirow{3}{*}{0.62} \\
\hline Tubulointerstitial & $15(14 \%)$ & $66(19 \%)$ & $56(18 \%)$ & \\
\hline Others, unknown & $84(76 \%)$ & $261(74 \%)$ & $220(72 \%)$ & \\
\hline $0-6$ HLA mismatches $0 / 1 / 2 / 3 / 4 / 5$ & $5 / 2 / 35 / 25 / 12$ & $15 / 3 / 134 / 52 / 44$ & $18 / 2 / 136 / 38 / 30$ & 0.1 \\
\hline \multicolumn{5}{|l|}{ Recipient body weight, $\mathrm{kg}$} \\
\hline Mean \pm SD & $76.2 \pm 13$ & $66.5 \pm 10$ & $57.5 \pm 10$ & \multirow[t]{2}{*}{0.0003} \\
\hline Range & $49-117$ & $45-111$ & $32-86$ & \\
\hline \multicolumn{5}{|l|}{ Donor body weight, $\mathrm{kg}$} \\
\hline Mean $\pm \mathrm{SD}$ & $61.9 \pm 10.4$ & $70.5 \pm 10.8$ & $82.9 \pm 13.5$ & \multirow[t]{2}{*}{0.000} \\
\hline Range & $44-90$ & $44-111$ & $54-120$ & \\
\hline
\end{tabular}

\section{Immunosuppression}

The CsA doses (mg/kg/day) were comparable in the 3 groups at 3 months after transplantation; however, although the low group received significantly less than other groups, the CsA levels were comparable at that time as shown in table 2. At 1 year, the CsA doses in the 3 groups were comparable: low group $2.1 \pm 0.6 \mathrm{mg} / \mathrm{kg} / \mathrm{day}$; medium group $2.4 \pm 0.7 \mathrm{mg} / \mathrm{kg} / \mathrm{day}$, and high group $2.2 \pm$ $0.5 \mathrm{mg} / \mathrm{kg} /$ day $(\mathrm{p}=0.15)$.

\section{Graft Function}

Delayed diuresis, defined as diuresis of more than $10 \mathrm{~min}$ after the end of the anastomosis, and acute tubular necrosis were comparable between groups (table 2). The overall frequencies of acute rejection episodes were comparable in the 3 groups (table 2), but the frequency of late rejection episodes (data not shown) 1 year or more after transplantation was significantly higher in the low group (2.3 episodes/patient vs. 1.3 and 1.1 episodes/patient in the medium and high groups, respectively; $\mathrm{p}<0.05$ ). Chronic allograft nephropathy was diagnosed in 37,21 , and $21 \%$ of the low, medium and high groups, respective- ly. These differences are statistically significant $(\mathrm{p}=$ 0.000).

\section{Graft and Patient Survival}

There was a statistically significant difference in the 5and 10-year graft and patient survival according to Kaplan-Meier survival curves as shown in table 3. At 1 year there was no difference in graft and patient survival. Using Cox regression models the identified predictors of graft survival are D/RBWR and donor sex (parameters considered: recipient age and gender, pretransplant dialysis, recipient and donor age and sex, 0-6 HLA mismatches, ischemia time, basal immunosuppression, immediate diuresis, and D/RBWR). Table 4 shows the clinical outcome and clinical grading of functioning grafts at last follow-up of the 3 groups.

Causes of Graft Loss. Chronic allograft nephropathy and recurrent acute rejection were the most common causes of graft loss in the 3 groups. Death with a functioning graft was significantly less common in the medium and high groups than in the low group. There was no difference in the other causes of graft loss among the 3 groups (table 5). 
Table 2. Post-transplant follow-up variables

Table 3. Patient and graft survival (Kaplan-Meier)

Table 4. Patient and graft outcome at last follow-up

Effect of Donor/Recipient Body Weight Mismatch on Kidney Transplantation Outcome

\begin{tabular}{lllll}
\hline & $\begin{array}{l}\text { Low group } \\
(\mathrm{n}=110)\end{array}$ & $\begin{array}{l}\text { Medium group } \\
(\mathrm{n}=355)\end{array}$ & $\begin{array}{l}\text { High group } \\
(\mathrm{n}=311)\end{array}$ & $\mathrm{p}$ \\
\hline Delayed diuresis & $3(2.7 \%)$ & $10(2.8 \%)$ & $19(6.1 \%)$ & 0.08 \\
ATN & $2(1.8 \%)$ & $9(2.5 \%)$ & $11(3.5 \%)$ & 0.69 \\
Acute rejection & $59(54 \%)$ & $194(55 \%)$ & $173(56 \%)$ & 0.61 \\
Late acute rejection & $24(21.6 \%)$ & $46(13.0 \%)$ & $40(12.9 \%)$ & 0.046 \\
CsA at 3 months & & & & \\
$\quad$ & $3.8 \pm 1.1$ & $4.6 \pm 0.8$ & $4.9 \pm 1.2$ & 0.05 \\
$\quad$ Dose, mg/kg/day & $175 \pm 75$ & $170 \pm 78$ & $172 \pm 80$ & 0.14 \\
$\quad$ Level, ng/ml & $2.76 \pm 1.68$ & $1.53 \pm 0.59$ & $1.40 \pm 0.68$ & 0.01 \\
Hypertension & $91(83 \%)$ & $269(76 \%)$ & $242(78 \%)$ & 0.04 \\
Diabetes mellitus & $18(16 \%)$ & $50(14 \%)$ & $40(13 \%)$ & 0.06 \\
Infection & $28(25 \%)$ & $89(25 \%)$ & $68(22 \%)$ & 0.5 \\
Malignancy & $4(3.6 \%)$ & $10(2.8 \%)$ & $4(1.3 \%)$ & 0.03 \\
Chronic rejection & $41(37 \%)$ & $73(21 \%)$ & $66(21 \%)$ & 0.0001 \\
\hline
\end{tabular}

ATN $=$ Acute tubular necrosis.

\begin{tabular}{|c|c|c|c|c|c|c|c|}
\hline & \multicolumn{2}{|c|}{$\begin{array}{l}\text { Low group } \\
(\mathrm{n}=110)\end{array}$} & \multicolumn{2}{|c|}{$\begin{array}{l}\text { Medium group } \\
(\mathrm{n}=355)\end{array}$} & \multicolumn{2}{|c|}{$\begin{array}{l}\text { High group } \\
(\mathrm{n}=311)\end{array}$} & \multirow[t]{2}{*}{$\mathrm{p}$} \\
\hline & $\%$ & $\mathrm{n}$ & $\%$ & $\mathrm{n}$ & $\%$ & $\mathrm{n}$ & \\
\hline \multicolumn{8}{|l|}{ Patient } \\
\hline 1 year & 97 & 107 & 99 & 352 & 99 & 308 & 0.14 \\
\hline 5 years & 81 & 89 & 85 & 302 & 92 & 286 & 0.04 \\
\hline 10 years & 45 & 50 & 70 & 249 & 81 & 252 & 0.01 \\
\hline \multicolumn{8}{|l|}{ Graft } \\
\hline 1 year & 96 & 106 & 98 & 348 & 98 & 305 & 0.21 \\
\hline 5 years & 71 & 78 & 80 & 284 & 88 & 274 & 0.01 \\
\hline 10 years & 28 & 31 & 41 & 145 & 51 & 159 & 0.05 \\
\hline
\end{tabular}

\begin{tabular}{|c|c|c|c|}
\hline & $\begin{array}{l}\text { Low group } \\
(\mathrm{n}=110)\end{array}$ & $\begin{array}{l}\text { Medium group } \\
(\mathrm{n}=355)\end{array}$ & $\begin{array}{l}\text { High group } \\
(\mathrm{n}=311)\end{array}$ \\
\hline \multicolumn{4}{|l|}{ Condition of the patients } \\
\hline Living with functioning graft & $67(61 \%)$ & $267(75 \%)$ & $234(82 \%)$ \\
\hline Living on dialysis & $19(18 \%)$ & $47(13 \%)$ & $40(13 \%)$ \\
\hline Died with functioning graft & $11(10 \%)$ & $17(5 \%)$ & $14(4 \%)$ \\
\hline $\begin{array}{l}\text { Died on dialysis } \\
\mathrm{p}=0.01\end{array}$ & $13(12 \%)$ & $24(7 \%)$ & $3(1 \%)$ \\
\hline \multicolumn{4}{|l|}{ Clinical grading of functioning grafts } \\
\hline Living with functioning graft & 67 & 267 & 234 \\
\hline Good $(\mathrm{SCr} \leq 1.5 \mathrm{mg} / \mathrm{dl})$ & $15(22 \%)$ & $151(57 \%)$ & $128(55 \%)$ \\
\hline Moderate $(\mathrm{SCr}>1.5-\leq 3 \mathrm{mg} / \mathrm{dl})$ & $28(42 \%)$ & $100(37 \%)$ & $94(40 \%)$ \\
\hline $\begin{array}{l}\text { Poor }(\mathrm{SCr}>3 \mathrm{mg} / \mathrm{dl}) \\
\mathrm{p}=0.04\end{array}$ & $24(36 \%)$ & $16(6 \%)$ & $12(5 \%)$ \\
\hline $\mathrm{SCr}=$ Serum creatinine. & & & \\
\hline
\end{tabular}


Table 5. Causes of graft loss

\begin{tabular}{|c|c|c|c|}
\hline & $\begin{array}{l}\text { Low group } \\
(\mathrm{n}=43)\end{array}$ & $\begin{array}{l}\text { Medium group } \\
(\mathrm{n}=88)\end{array}$ & $\begin{array}{l}\text { High group } \\
(\mathrm{n}=77)\end{array}$ \\
\hline Death with function & $11(26 \%)$ & $17(19 \%)$ & $14(18 \%)$ \\
\hline Technical loss & - & $3(3 \%)$ & - \\
\hline Chronic allograft nephropathy & $29(67 \%)$ & $48(55 \%)$ & $42(54 \%)$ \\
\hline Recurrence & - & - & $3(4 \%)$ \\
\hline Others, unknown & $3(7 \%)$ & $20(23 \%)$ & $18(24 \%)$ \\
\hline
\end{tabular}

$\mathrm{p}=0.05$

Complications. Significantly more patients in the low group developed post-transplantation hypertension and proteinuria than in other groups $(\mathrm{p}<0.05)$. There was no difference between the groups with respect to medical or surgical infections, malignancy, hepatic dysfunction or urological complications (table 2).

Causes of Death. There was no difference in the cause of death between the 3 groups ( $p=0.27$ ). The most common causes of death were infections $(35.7 \%)$ and cardiovascular diseases $(21.4 \%)$.

\section{Discussion}

Chronic rejection remains a mystery, and a non-immunologic hypothesis linking the chronic decline of graft function to hyperfiltration due to nephron under-dosing is very attractive. Hyperfiltration injuries secondary to an inadequate nephron mass are likely to have an additive effect on the damage caused by immune-mediated injuries, and the final pathway of glomerulosclerosis is likely to be initiated when a critically low level of functioning nephron mass is reached [17]. The hyperfiltration hypothesis has been difficult to prove in clinical transplantation, because measures of functioning renal mass are currently unavailable, and there may be substantial variability in the baseline nephron numbers across otherwise healthy populations.

The results of this study suggest that a small donor kidney in a large recipient could be a major risk factor for late allograft failure. However, as in any retrospective analysis, a statistical association does not prove causality, and the mechanisms that may explain the association cannot be determined from these results. Previous studies investigating the effect of donor/recipient size have produced conflicting results both in living-donor $[9,12,14,18]$ and cadaveric-donor transplantations $[8,10,11,13,19,20]$.
Kasiske et al. [10] could not demonstrate the effect of donor/recipient size mismatch on short-term (4 months) outcome after kidney transplantation; however, the risk of graft failure was increased by $43 \%$ for large recipients from small donors, which was statistically significant. A similar observation was reported by Nishimura et al. [12] who found the donor kidney weight/recipient body weight ratio in adult living-donor kidney transplant patients a significant predictor of graft survival. In contrast to our results, Shaheen et al. [14] did not find any impact of donor weight on cumulative graft survival in living-donor transplants. One reason for this difference in results could by explained by differences in sample size and the other reasons may be related to the study design or the duration of follow-up.

Obesity has conflicting results on patient and graft survival in many series [21, 22]. Thus, it was important to distinguish the effects of obesity from effects of donorrecipient size disparities. Kasiske et al. [10] found that obese individuals who receive a matched kidney may not be at increased risk of late graft failure. In our series we exclude obese patients with a body mass index of $\geq 35$.

Interestingly, our results demonstrate that large donor-recipient body weight mismatches may contribute to death with a functioning graft. In fact, this is not necessarily inconsistent with the role of hyperfiltration, or other factors which may cause the increased risk of graft failure associated with a small kidney. Indeed, treatment with additional potent immunosuppression which may increase the risk of infection, higher incidence of post-transplant hypertension, proteinuria and diabetes mellitus and other correlates of poor graft function, could explain why transplanting a kidney that is too small for a large recipient increases mortality after transplantation.

The mechanisms which could explain this association between high donor-recipient body weight mismatches and inferior graft and patient survival may be a matter of 
debate. We could speculate that the compensatory hemodynamic changes associated with small kidneys into large recipients may lead to proteinuria and hypertension which could cause injuries to the graft. Moreover, these compensatory hemodynamic changes could be a proinflammatory trigger leading to alloantigen-dependent kidney damage. The use of calcineurin inhibitors in these patients with its potential nephrotoxicity added to hyperfiltration hemodynamics may have a deleterious impact on graft outcome. Thus, there are many plausible mechanisms for the negative effects of donor-recipient body weight mismatches on graft and patient survival after kidney transplantation.
In conclusion, our findings provide direct evidence of a substantial effect of initial donor-recipient body weight mismatches on graft and patient outcome. Although the actual donor kidney weight at the time of transplantation seems to be the best surrogate index for nephron number, routine weighing of the donor kidney at the time of transplantation may not be normal practice.

During donor and recipient matching, both the potential weight of the donor kidney and the recipient body weight should be considered in terms of graft function, until a method to measure renal parenchymal volume and number more precisely has been developed.

\section{References}

1 Brenner BM, Milford EL: Nephron under dosing: A programmed cause of chronic renal allograft failure. Am J Kidney Dis 1993;21:S66S72.

2 Heeman UW, Azuma H, Tullius SG, Mackenzie H, Brenner BM, Tilney NL: The contribution of reduced functioning mass to chronic kidney allograft dysfunction. Transplantation 1994;58:1317-1322.

3 Bio MJ: Nonimmunologic causes of late renal graft loss. Kidney Int 1995;47:49-54.

4 Texasaki PI, Gjertson DW, Cecka JM, Takemoto S: Fit and match hypothesis for kidney transplantation. Transplantation 1996;62: 441-445.

5 Neugarten J, Srinivas T, Tellis V, Silbeger S, Greentein S: The effect of donor gender on renal allograft survival. J Am Soc Nephrol 1996;7:318-324.

6 Moreso S, Seron D, Anunciada AI, Hueso M, Ramon JM, Fulladosa Y, Gill-Vernet S, Alsina J, Grinyo JM: Recipient body surface area as a predictor of post-transplant renal allograft evaluation. Transplantation 1998;65:671-676.

7 Alcalde G, Escalloda R, Rodrigo E, Cotorruelo JG, Zubimendi JA, de Francisco ALM, Arias M: Disproportion between kidney graft and recipient size is the main predictor of long-term proteinuria. Transplant Proc 1997;29:127128.

Effect of Donor/Recipient Body Weight Mismatch on Kidney Transplantation Outcome
8 Vianello A, Calconi G, Amici G, Chiara G, Pignata G, Maresca MC: Importance of donor/ recipient body weight ratio as a cause of kidney graft loss in the short to medium term. Nephron 1996;72:205-211.

9 Kim SJ, Kim YS, Lim MS, Moon JI, Park K: True living donor kidney weight-to-recipient body weight ratio influences post transplant 1year renal allograft function. Transplant Proc 1998;30:3120.

10 Kasiske BL, Snyder JJ, Gilbertson D: Inadequate donor size in cadaver kidney transplantation. J Am Soc Nephrol 2002;13:2152-2159.

11 Cho YW, Terasaki PI, Cecka JM, Gjertson DW, Takemoto S: Should excessive height and weight differences between the kidney donor and recipient be avoided? Transplant Proc 1997;29:104-105.

12 Nishimura Y, Tomikawa S, Beck Y, Nomura Y, Ando Y, Kikuchi K, Ichikawa N, Meigata K, Muto T, Kuzahara K, Degawa H, Nagao T, Uchida $\mathrm{H}$ : Kidney graft weight as an important long-term graft survival. Transplant Proc 1998; 30:107-110.

13 Pourmand G, Taheri M, Mehrsai AR, Nourijelyani K: Impact of donor nephron mass on outcome in renal transplantation. Transplant Proc 2001;33:2828-2829.

14 Shaheen FAM, Al-Sulaiman M, Moussa D, ElDin ABS, Hawas F, Fallatah A, Bill P, Sheikh JA, Al-Menawy L, Ramprasad KS, Al-Khader AA: Impact of donor/recipient gender, age, HLA matching and weight renal transplantation. Transplant Proc 1998;30:3655-3658.
15 Moon IS, Kim YG, Park JH, Kim YS, Kim JC, Yun JY, Bang BK, Koh YB: Influence of donor kidney size on immediate renal function (1 month) in kidney transplantation. Transplant Proc 1998;30:3666.

16 Dunnill MS, Halley W: Some observations on the quantitative anatomy of the kidney. $\mathrm{J} \mathrm{Pa}$ thol 1973;110:113-121.

17 Nyengaard JR, Bendtsen TF: Glomerular number and size in relation to age, kidney weight, and body surface in normal man. Anat Res 1992;232:194-201.

18 Andrews PA, Campton F, Koffman CG. Influence of donor/recipient size in living donor kidney transplantation. Transplant Proc 2001; 33:1146-1147.

19 Lee LS, Auersvald LA, Claus EB, Bia MJ, Friedman AL, Lorber MI, Basadonna GP: Body size mismatch between donor and recipient and the development of chronic rejection in renal transplantation. Transplant Proc 1997; 29:111.

20 Feldman HI, Fozio I, Roth D: Recipient body size and cadaveric renal allograft survival. J Am Soc Nephrol 1996; 7:151-154.

21 Howard RJ, Thai VB, Patton PR, Hemming AW, Reed AI, Van der Werf WJ, Fujita S, Karlex JL, Scornik JC: Obesity does not portend a bad outcome for kidney transplant recipients. Transplantation 2002;73:53-55.

22 Gill IS, Hodge EE, Novick AC: Impact of obesity on renal transplantation. Transplant Proc 1993;25:1047-1049. 